\title{
Imitation as a Skill in Language Learning: The Aid to Achieving Fluency of the Target Language
}

\section{Faramarz Samifanni}

Fukuoka International University of Health and Welfare $\overline{7} 814-0001$, Fukuoka Prefecture, Fukuoka city, Sawara Ku, Momochihama 3-6-40, Japan

Email: $\underline{\text { samroza730@gmail.com }}$

\author{
Article History \\ Received: April 5, 2020 \\ Revised: April 29, 2020 \\ Accepted: May 7, 2020 \\ Published: May 10, 2020 \\ Copyright @ 2020 ARPG \\ \& Author \\ This work is licensed \\ under the Creative \\ Commons Attribution \\ International \\ (5) (1) $C C$ \\ BY: Creative Commons \\ Attribution License 4.0
}

\begin{abstract}
This study aims to describe how imitation can aid in language learning and in achieving fluency in the target language. A deductive-axiomatic research design using thematic analysis based on data mining and personal experiences of the researcher revealed that a positive and conducive environment is a key factor in successful language immersion and imitation. Additionally, adapting with a positive, new community reinforces imitation skills. Furthermore, imitation must be properly employed to guarantee the success of language learning and communication. Language learners have to know the skill in producing the correct sound that is comprehensible by the native speakers to avoid miscommunication. Nevertheless, it is emphasized that role-playing, being an application of imitation must be taught enjoyably to encourage positive output in language learning. A child first learned how to utter a word before he/she could read and write. It seems that this basic logic in language learning is disregarded within the second language learning curricula.
\end{abstract}

Keywords: Fluency; Immersion; Modeling; Observation; Social interaction.

\section{Introduction}

Language is a "skilled activity". Imitation could take various roles in the process of learning and the development of language skills (Allott, 2003). It is the act of mimicking the facial expressions, movements, and actions of someone else. The learner copies the behavior of the model to achieve a similar objective. Although the capacity to imitate is not agreed to be inborn or not; "imitation of facial expression", "body movements", and "gestures" are existing during the first years of life (Heimann, 2002).

As posted by Meltzoff and Prinz (2002) in their "developmental theory of imitation", the learner as observer uses visual awareness as his or her basis for the application of the imitated behavior. Their study shows that sounds; and representing these sounds into familiar symbols and sign is multimodal; young learners are capable of delayed imitation, a possible result from "echolalia" or speech repetition as a major stage towards the development of symbols. What seems clear from the above discussion is the multimodal connection between one's observation and action which is a remarkable foundation for imitation. This is also observable between "speech production and speech perception, and for the relation between gesture and speech."

Imitation involves complex mental abilities and plays a major part in the quest for knowledge (Hurley and Chater, 2005). Studies in developmental psychology have discovered that imitation happens in the early years of young learners and develops alongside several mental skills all through the age of maturity (Heyes, 2010). Imitation is important to numerous socio-cognitive skills; as a result, it "accelerates learning and multiplies learning opportunities" (Meltzoff et al., 2009). Imitation is an effective and competent approach to learning and has recognized several influences affecting learners' efficient imitation in acquiring competence (Meltzoff and Prinz, 2002).

The concern is on what role imitation plays in the origins of language learning, in language development and its chronology, and the use of language imitation in society (Allott, 2003). However, these concerns can be dealt with a quite rational means of proving that human beings, as social beings tend to apt themselves to their social environment should they desire to do so.

The use of imitation is apparent in most fields of the activities of people. This contains physical reactions (Nielsen and Christie, 2008). Many properties in language and learning involve imitation. These include but not limited to lexical and syntactic alignment and speech rate (Pickering and Garrod, 2004). Current statistics show capabilities not in existence from being born to start developing from the second year of a person's life and continue throughout that person's lifespan. Moreover, imitation is not inherited by genes, but that it is a social skill learned (Gottlieb, 2007). 
Magocsa (2011), dealt with the issue of imitation and language learning at a very young age. The data for the study has been collected in the course of half a year while observing a young learner's language and intellectual development. In observing the learner's target language development, it is concluded that at this age both imitation and spontaneous speech production contribute to target language development. Anyone watching a child mature can confirm that "imitation is a foundation of learning". Furthermore, self-analysis revealed that imitation played an important part in adult learning. Essentially, imitation is predominant in daily decision-making (Apesteguiaa et al., 2007). Csaszar and Siggelkow (2010), highlighted the instances which improve the span of imitation. Moreover, the outcomes focus on the two-key purpose of imitation: replicating achievers' performance also inquiring by removing unnecessary details from the schema. Both purposes of having specific structures for an effective application. "Imitation learning" is used in solving specific isolated tasks. It typically involves cautious work or a substantial number of models (Duan and Andrychowicz, 2017).

Some would argue that pronunciation is commonly educated on the basis that imitation is the normal method for its attainment. If this is wrong, then different methodology ought to give improved outcome than the one at present. This erudition procedure is more multifaceted than plain imitation but brings about the most accepted structure for the principal demonstration of speech sounds. Consequently, some ancient problems in speech can be single-minded and an incorporated developing notion of creation and awareness comes out. Undoubtedly imitation includes connecting and relating the mind with physical movement. The same goes for language as it is a mental process in which it gives the body orders to make sounds (Allott, 2003).

\subsection{Research Problem}

The above-mentioned studies involved factors such as the measure of imitation as a behavior, performance replication, the importance of pronunciation in imitation, and intellectual development involved in imitation. However, these studies do not tell us how to properly employ imitation. This has led to the conceptualization of this paper.

\subsection{Research Objective}

This study aimed to describe how imitation can aid in language learning and in achieving fluency of the target language.

\section{Material and Method}

This section comprises the research design, instrument and procedure/theory generation, data analysis, and theoretical sampling/ theory confirmation.

\subsection{Research Design}

This article employed a mixed qualitative method; deductive- axiomatic design to generate theory (Arnold et al., 2010; Zalaghi and Khazaei, 2016) as described in the lived experiences of the author about a phenomenon; English language (Creswell, 2013). A deductive- axiomatic procedure begins with the general principles and ends with specific statements, which can be best used for arguments based on laws and other widely accepted principles (Arnold et al., 2010; Zalaghi and Khazaei, 2016).

\subsection{Instrument and Procedures/ Theory Generation}

This study used desk research and the author's lived knowledge and observations. The theory development involved the formulation of the set of axioms based on the analyses of data gathered online. Afterward, propositions were formulated after creating the connections amongst the axioms. Then, the author's lived knowledge and observations were used to verify the arguments. The pre-mining tasks which involved removing irrelevant and undependable information, and data integration that concerns the accumulation of facts from several sources to a particular location and a shared format. Subsequently, are the post-mining tasks involving evaluation focusing on pattern identification that represents knowledge, and knowledge presentation which provides discovered rules through visualization and various knowledge portrayal methods.

\subsection{Theory Generation Process}

The theory generation process is shown in the figure 1 below.

Figure-1. Theory Generation Process (Glasser, 1978)

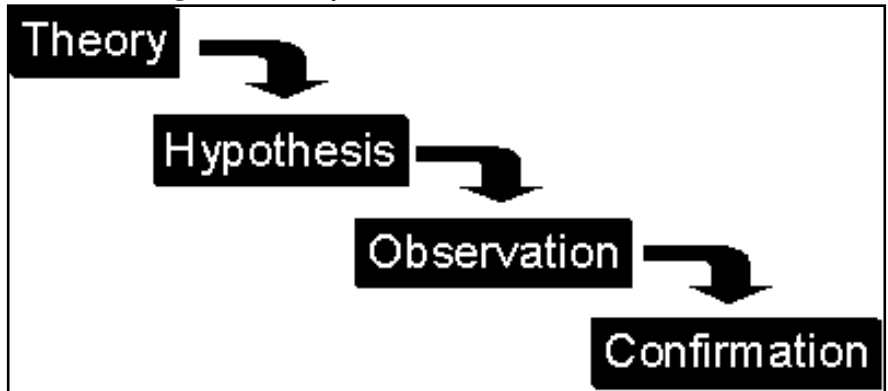




\subsection{Data Analysis}

Similar with other studies using deductive-axiomatic process in theory development, the axioms and propositions were derived after open coding. In this process of coding and analysis, the researcher attempts to consolidate the data through constant comparison and some deductive relations.

\subsection{Theoretical Sampling/ Theory Confirmation}

In this stage, the researcher saved, encrypted, and evaluated the information mined then analyzed which truths must merge to create axioms and propositions. The emerging and selected axioms will give more direction to create propositions. The criteria of theoretical purpose and relevance were applied and to the ongoing data analysis at the same time as the theory is being built deductively. This method ensures the data's relevance to the emerging theory. The data mining technique was used to validate the generated theory in this study.

\subsection{Formulated Axioms}

The theories on language learning were reviewed and the following axioms were used in formulating and categorizing the proposition of the study.

\subsubsection{Axiom 1: Language is Learned Through Imitation and Full Emersion}

Weigand (2003), and Schoop (2001) considered that language is utilized for trading of information such as statements or reports, and for doing actions like vows, declarations, commands, etc. Additionally, Vygotsky (1978) clearly emphasized that the chief feature of learning is the analysis of the learner's potential for improvement through collaboration from his or her weakness to his or her strength with imitation. Meaning, the focus of imitation is on innovation not on replication.

Meltzoff (2007), claimed children's' relevant learning is a combination of keen observation and interaction. He emphasized that beginning at birth, there appears to be a subtle relationship between learning through observation and learning through application. What newborns observe impacts what they will do, and what they are capable of alters their attention to the ideal and how they understand it. Since the effects of immersion may differ with people speaking the partner dialect to those natural speakers of English; immersion allows language learners to get an ample share of core academic content in their native language to share a classroom with native English speakers giving them an advantage in the partner language. Thus, language learners have an advantage in an immersion setting (Lindholm-Leary and Block, 2010).

Proper timing posted Shockley et al. (2009) is the key to effective communication. This skill depends on both motor and conversational coordination. For instance, a speaker does not want his pair to wait endlessly for a reply, nor interrupt while the other person is talking (Stivers et al., 2009).

\subsubsection{Axiom 2: Language Development is Skill-Based}

Rosselli et al. (2014), reviewed and examined the relationship of observable language changes in human development and the processes of brain development across age groups. They highlighted two principal measurements of language development these include: naming (regarded a major measure of verbal awareness) and oral fluency (considered as a chief measurement of speaking skill). Moreover, they emphasized that in early life there is an irregularity for language learning but this changes with time. From their alternative viewpoint, (Chater and Christiansen, 2018) "language-as-skills" structure, the child's challenge is an application, not hypothetical: the child learns to recognize and use the target or new language by involving in conversations. This view removes the pressure from nature and stressing instead of the cultural development of linguistics.

\subsection{Proposition}

Appropriate Imitation enables language learning: Language is learned through proper emersion, observation, imitation, modeling and social interaction.

\subsection{The Theory}

Imitation is the basic form of learning both the culture and the language. As the famous quote "When in Rome do as the Romans do." The learner would benefit most from imitating the way of speaking and the way of not just the language but also the gestures to learn the communication style. This would make others feel more at ease with the people he or she intends to communicate. Moreover, imitation would be productive when the learner feels unthreatened by the environment, he/she is exposed to. A positive experience of imitation will help the learner to be fluent in the target language.

\section{Results}

While communication starts from localization, language learning is enabled through imitation. As one immerses in the culture and models and interacts, the learner then begins learning how to communicate with the people of that society through the use of imitating the language first. Imitation therefore, by no doubt is the first thing people do in learning to use language. This is not only in language learning but also in acting and singing as well. Through imitation, a learner becomes closer to the culture of the people who the learner lives in or wants to communicate with. 


\section{Discussion}

The basic ways of learning to speak such as mimicking and imitating are our first ways of learning as we hear the sounds. First words in English like 'warer' to mean water and 'sharap' to mean shut up as had been learned by the researcher before coming to the United States as an 11-year-old learner, which he imitated before even relating their real meanings to the words he had studied before. Where he had learned that the expression 'Shut up' is an extremely rude word in his country of birth and his class status, he had no idea that there are many different cultural meanings attached to such words in the United States. The misunderstandings created a very different effect on the researcher's (learner's) psyche before his higher education and research. This means, it took forty years and profound research and international and multicultural immersion for him to untangle the complex to realize that the meaning of the words said to him was a total misunderstanding.

\subsection{Learning the Culture Through Imitation}

However, the notion that imitation is the second stage of language learning is clear by the next example which is also the researcher's many experiences in language learning and communication. While communication starts from localization (Samifanni, 2020), language learning is enabled through imitation. As one immerses in the culture and models and interacts, the learner then begins learning how to communicate with the people of that society through the use of imitating the language first. Imitation therefore, by no doubt is the first thing people do in learning to use language. This is not only in language learning but also in acting and singing as well. Through imitation, a learner becomes closer to the culture of the people who the learner lives in or wants to communicate with.

Imitation takes a huge segment of childhood. In each phase, individuals learn by observing, listening, and performing, enjoying hours of recurring games, replicating numerous jokes to one another, and parroting the lyrics of songs; these are few of the methods of how people imitate. "People learn social rules by imitation, studying facial expressions and body language - and, unsurprisingly, a big part of language is learned by imitation". Before learning a language, young learners spontaneously mimic "facial expressions including the sounds, intonations and volume of what they hear, and learning the accent of their native language well before understanding individual words." In their toddler years, they can utter some expressions (but can recognize more) and they increase their attempts to imitate. Young learners only imitate the language of their environment to later assist them in understanding "how the components of language all fit together and to work out what it all means" (Donnelly, 2017).

As posted in the investigation of Adank et al. (2010) whether "vocal imitation can improve comprehension of the language spoken in an unfamiliar accent". Post-training assessments revealed that when learners imitated, their improvement of oral language increased.

Meaning, it is not mostly about a keen focus on phonetic or the phonological differences that made the improvements. It showed that imitation alone was the main source of improvement in language comprehension. The results of their study correlate another study that proves by imitating in groups, learners improvements increase (Oztop et al., 2005). A technical understanding of the new or target language consists of constructions, its rules, semantics, and pragmatics. It is stressed that imitation and repetition are crucial in the process of learning. Old pattern practice can be conceptualized as a cognitive type of practice seen from the perspective of establishing connections of meaning in the target language (Yamaoka, 2006).

Oral communication as a dynamic ability is regarded as one of the primary cases that learners deal with when using a new language. Being highly competent in speaking and intelligibly communicating despite any situation the speaker's faces, is seemingly the highest goal of every new language learners. Pronunciation is an expected and perhaps inseparable component of this verbal skill, and weakness in pronunciation can seriously affect the selfconfidence of the learner in verbally expressing oneself, it may also result in self-restraint in a group and failure to interact socially (Prodanovska, 2017).

Individuals learn from each other, through watching, modeling, and imitation. The researcher has used imitation on many occasions to learn another language. From his teacher, he had learned the word water to be pronounced WA-TER, but in the United States he understood through imitation that the word is pronounced "wa-rer". In the late 1970's when the researcher was about 12 or 13 years old, he was still new to English and fully immersed in English in a middle school, in the state of Florida where he was attending the last grade, he had encountered a word he had never heard before and through imitation, he had experienced his one of many culture shocks; a white classmate had called the researcher the word "Niger" of which the researcher had no idea of what it meant but by the tone of the classmate it sounded like a bad word. The reason the classmate had called the researcher the "N" word was because of the researcher's curly hair and tanned skin due to the outstanding Florida sunlight and the often beach-going of the researcher.

So, the researcher imitated the word and in the first chance he had, he retaliated against the white classmate the same word thinking that it was a bad word that the classmate deserves to wear it on his own. This incident happened while playing soccer in the school field where the black coach heard it and stopped the game. The coach asked whether the researcher knew the meaning of the word and not wanting to lose face, the researcher said yes but the coach did not believe because he knew the researcher did not have full knowledge of the word attached to the culture and the researcher was not yet a native speaker. The researcher's positive response to knowing the meaning was due to shame and embarrassment and fear of being bullied more by other classmates. The point of the incident is that through imitation, words are used and through cultural and personal experiences, meanings are learned. Situated immersion had its negative psychological side effects to the researcher. Looking back over forty years after the incident, the researcher believed this was a perfect example and proof of two notions: the use of imitation and the Ting-Tommy's Face Negotiation Theory in action. This is contrary to "Lave's theory of situated learning" that 
language usually occurs as a task of the movement, circumstance, and culture in which it occurs. Lave is very idealistic and he does not consider the adverse situations in the "language learning processes". As revealed in Parra et al. (2014) study of monolingual Spanish-speaking learners, results indicated there are many negative consequences of learners studying in the fully immersed language class due to their lessons.

\subsection{Proper Imitation Through Application}

One of the most significant and challenging problems that learners deal with in mastering the English language is pronunciation. In an actual situation, the moment an individual speaks, the "first thing" people notice is the speaker's pronunciation. In daily interactions, a person typically can make use of simpler words or expressions to relay meaning in an unfamiliar terminology. In reality, people will recognize almost instantly if his or her pronunciation is acceptable or not judging from the few initially uttered ordinary expressions or vocabulary. If the speaker has a 'poor pronunciation with a very strong foreign accent', listeners consider him or her as a 'bad English speaker' and the person's good vocabulary and grammar cannot even neutralize such judgment (Speak, 2014).

In Canada, learning the word "Eh" (pronounced Ei) can be quite distinct to the Canadian saying as to: "Isn't it? or, It's true, isn't it?" This was easily imitated once in Canada. In Japan, the researcher quickly imitated what was heard and sounded unique by a certain fish seller in a supermarket, and to this day can sound exactly like that fish seller. When the researcher started exploring Cebu and the Philippines as a whole he quickly learned the word "diba" due to its similarity to the word "Desho" in Japanese which similarly means "eh" in Canada.

The most important point the researcher has learned throughout his experiences is that correct pronunciation cannot be learned in books but through social interaction. In Japanese, the word "I understand" is: "Wakarimashita" and is mostly mispronounced if the emphasis is on the "Shi" of the "Wakarimashita". Many non-Japanese who learn Nihongo through books often pronounce the word not sounding Japanese. The Japanese pronounce the word without or with a very quick way of "Shi" so that it sounds more like "Wakarimashta".

Proper imitation and pronunciation imply a proper and smoother way of communication. Connecting imitation and pronunciation to the meaning will imply true communication; and mispronunciation could lead to misunderstanding and miscommunication.

In Japan, the word "Kawai" and "Kowai" could have negative consequences; the first means "cute" while the second means "scary". Therefore, correct pronunciation can be considered as an imperative sub-objective in speech development. In almost all nations there are sub nations with their dialects. In learning a language, it can clearly be said that the level of fluency relates to proper pronunciation. Lack of proper pronunciation in the area could hamper success in the learner's future about profession, education, and others. Moreover, it is considered as the most important notion that a learner who can master the pronunciation of a language first, he or she would reach fluency sooner. Researches in language learning have uncovered that basic oral communication does not require great intelligence. If a smoother message exchange can be attained, successful communication can be recognized too (Prodanovska, 2017).

Knowing enough vocabulary is useless if a learner cannot articulate expressions or words properly and nobody can comprehend the meaning the speaker (learner) is trying to convey. It is much worse if errors in pronunciation result in misunderstanding (Speak, 2014). In a study, Rojczyk (2012) experimented with 'Polish learners on imitation resulted in solid proof that imitation can greatly affect the positive outcome of learning.

Some learners concluded that "they can communicate in the English language" because their teacher and classmates easily communicate with them. What the learners are missing is the truth that in language learning the language must be put in real use and not just in the classroom. The most effective method to access one's self is through active communication with people of the target language. If the native language speakers can comprehend the learner's new language and confirm the learner's correct pronunciations, then the learner can be confident of the new language fluency. An unacceptable accent can lead to negative feelings, misinterpretation, and unsuccessful communication (Speak, 2014).

Some studies highlight the importance of role-playing as an application of imitation; Aliakbari and Jamalvandi (2010) claimed that through the use of role-playing, students can feel and experience life situations in make-believe. Active play-acting is encouraging feeling for learners to use the new language and copy the gestures of native speakers and eventually use the target language. In Liu and Ding (2009) findings, the notion of role-playing as a process of teaching and learning as a technique that has a very high rank.

In a classroom setting, imitation applied and observed in activities like "role-play" is where the learners portray English in a "real-life" context. Students portray certain or popular roles using the language in various scenes (Jackson and Back, 2011). Moreover, Bongard and Hornby (2013) claimed, that the use and application of another language mandate learner the sense of being useful as members of the group. This concept of the group working towards the application of activities such as role-playing reinforces students active community relations. Guanoquiza (2013), posited that learners require exposure to a welcoming and motivating atmosphere to advance their existing communication skills.

In 1990 as the researcher went to Japan to experience his fourth culture and live among the beautiful people of Japan, he found himself puzzled by the utterances of a fish seller inside a famous department store in Inage City, Chiba prefecture called "Saty". The seller in a deep unique voice uttered: "Saaaa Dozo sa dozo irashai masen Yasuiyoooo" (Hey! Please... welcome it is cheap). This was the exact words the researcher imitated and to this day remembers the exact sounds. While for many months and even years the researcher had no idea on the meaning of the words, he could imitate that man to the exact sound coming from his throat. Since the year 2010 where the researcher has lived both in Japan and the Philippines, he has managed to puzzle many Filipinos by his way of 
imitating certain words which at times had made the Filipinos thought that the researcher is fluent in the Filipino languages of Cebuano and Tagalog. The researcher has mastered the expressions of 'Pero' (but), 'Mahal' (expensive), 'Di ba' (isn't it/ right) and 'Uy' (hey), 'Hala' (oh) and 'Sige na' (please/ let's go) and a few more in their uses through learning to imitate. It seemed that an accommodating environment helped the researcher strive to achieve the specific sounds and pronunciation of the Filipino language.

\subsection{Productive Imitation in a Stress-Free Environment}

This is also true with when the learning environment is "stress-free and accommodating", learners trust and feel safe to practice and use words in more realistic circumstances and are more creative. As such, teachers play a very important role in giving the learners chances to experiment with the new language (Afdillah, 2015). Research after research; it is shown that the primary significance of utilizing role-play expressed by Ladousse (2004), is that it can be enjoyable, realistic and motivating for even the unmotivated learner to be stimulated as the experience helps the learner communicate using the new language.

A study of Kokkinaki and Kugiumutzakis (2000) on imitation in the first year of infancy showed that imitation works. Sound imitation is very normal during the first year of infancy in social interactions. The researcher, recalls his daughter in the later age of one to attempt to stand and try to utter words to children while see them play nearby in a shopping mall's children's area.

A more interesting point on imitation is that it is better with assistance. During the interaction, learners teach one another and focus on practice and knowledge. In learning to imitate the learners tend to unconsciously do without notice or thought. The interaction causes people to learn many things from each other. All activities can be as a result of actions learned either face to face or from distance and mostly through imitation (Zukow-Goldring, 2012).

Scientifically speaking, the `spontaneous imitative behavior` noticed in humans seems to be based on the matching system of the brain's ability to imitate like a mirror reflects (Schwartz et al., 2012). This 'speech-imitative behavior' continues into maturity and provides various sociolinguistic roles. As an example, grown-ups can adopt a new dialect fairly easily in new surroundings (Delvaux and Soquet, 2007). Replication seems to be provoked by the need to conform to social acceptance demand. Moreover, speakers also exhibit a talent for imitating so that they can comply with conformity from their listeners (Shepard et al., 2001). It seems that learners use imitation because they want to feel that they belong or blend-in to the environment where they are exposed.

\section{Conclusion}

Language learning cannot be achieved by just reading a book. It is important to immerse the learner in the environment where he or she can learn the target language. Exposing a child to the target language will make him/ her observe and imitate the language and model it. However, it must be a concern of every language learner that the learning environment is not always friendly and ideal, so one must ensure how to interact accordingly. Imitation is not copying the words because it entails proper ways in producing the sounds of the word in the target language as some words could be confusing and the message could be misinterpreted with just a slip of a letter.

While full immersion is open to great debate, the belief is that if students, who are in a class where the teacher does not speak their language, will be motivated to learn the teacher's language. Many native English speaker teachers happily place the English only rule in their class and do not even make any attempt to study the culture of their learners' language. Regretfully, the results are not well studied, and supporting evidence are not proven clearly as to full immersion classes in the learner's own country would assist a learner to learn another language fluently. After all, most of the lessons are taught with the belief that English is global and that if you can speak English you can communicate with others who can also speak English. This research seemed to clarify that English and any language cannot be globalized in such terms as even those who speak English natively have great tendencies for miscommunication. Also, it seems like teachers who are mostly supportive of full immersion of English language teaching are naive of the learners' culture and the language to begin with and would like such programs simply because they are weak at learning to communicate in another language themselves.

\section{Acknowledgements}

My deepest gratitude the Creator of all Good Thoughts, Good Words and Good Deeds as well as to the leaders of my university, Director/Owner Doctor Kunitaka Takagi, President Doctor Tsutomu Imaizumi, Vice President Doctor Hitoshi Maruyama and the heads of OT, PT and ORT departments for their support and positivity in allowing me to improve the students' language communication skills.

Finally, I extend my gratitude to the friendly and cheerful people of the Philippines, who made my life more meaningful.

\section{References}

Adank, P., Hagoort, P. and Bekkering, H. (2010). Imitation improves language comprehension. Psychological Science, 21(12): 1903-09. Available: https://doi.org/10.1177/0956797610389192

Afdillah, N. (2015). The effectiveness of role play in teaching speaking. Master dissertation. Jakarta, Indonesia. http://repository.uinjkt.ac.id/dspace/handle/123456789/26710 
Aliakbari, M. and Jamalvandi, B. (2010). The impact of 'role play' on fostering efl learners' speaking ability: A taskbased approach. Pan-Pacific Association of Applied Linguistics, 14(1): 15-29. Available: https://files.eric.ed.gov/fulltext/EJ920501.pdf

Allott, R. (2003). Imitation in Language and Speech. Available: http://cogprints.org/3111/1/imitation.htm

Apesteguiaa, J., Huckb, S. and Oechsslerc, J. (2007). Imitation-theory and experimental evidence. Journal of Economic Theory: 217-35. Available: https://doi.org/10.1016/j.jet.2006.07.006

Arnold, D. H., Arnold, K. and Arnold, V. (2010). Managing ethical risks and crises: Beyond legal compliance. Beijing Law Review, 1(1): 1-6. Available: https://doi.org/10.4236/blr.2010.11001

Bongard, J. C. and Hornby, G. S., 2013. "Combining fitness-based search and user modeling in evolutionary robotics." In 15th annual conference on Genetic and evolutionary computation. Amsterdam, The Netherlands.

Chater, N. and Christiansen, M. (2018). Language acquisition as skill learning. Current Opinion in Behavioral Sciences, 21: 205-08. Available: https://doi.org/10.1016/j.cobeha.2018.04.001

Creswell, J. (2013). Qualitative inquiry and research design: Choosing among the five approaches. SAGE Publications, Inc.: Thousand Oaks, CA.

Csaszar, F. A. and Siggelkow, N. (2010). How much to copy? Determinants of effective imitation breadth. Organization Science: 661-76. Available: https://doi.org/10.1287/orsc.1090.0477

Delvaux, V. and Soquet, A. (2007). The influence of ambient speech on adult speech productions through unintentional imitation. Phonetica. 145-73. https://doi.org/10.1159/000107914

Donnelly, L. (2017). The Importance of Imitation. Available: https://www.eardrops.co.nz/news/language-series-9the-importance-of-imitation

Duan, Y. and Andrychowicz, M., 2017. "One-shot imitation learning." In 31st Conference on Neural Information Processing Systems (NIPS 2017), Long Beach, CA, USA, . pp. 1-12.

Glasser, B. (1978). Theoretical sensitivity: Advances in the methodology of grounded theory. Sociology Press: Mill Valley CA.

Gottlieb, G. (2007). Probabilistic epigenesis. Dev. Sci., 10: 1-11. Available: https://doi.org/10.1111/j.14677687.2007.00556.x

Guanoquiza, C. (2013). The role-play as a teaching - Learning strategy for enhancing English levels in high school students in a Chilean context. Available: https://www.teachingenglish.org.uk/article/role-play

Heimann, M. (2002). Notes on individual differences and the assumed elusiveness of neonatal imitation. The Imitative Mind: Development, evolution, and brain bases, eds. A. N. Meltzoff and W. Prinz. Cambridge University Press: Cambridge. https://doi.org/10.1017/CBO9780511489969.005

Heyes, C. (2010). Mesmerizing mirror neurons. Neuroimage, 51: 789-91. Available: https://doi.org/10.1016/j.neuroimage.2010.02.034

Hurley, S. and Chater, N. (2005). Perspectives on Imitation: From Neuroscience to Social Science. MIT Press: Cambridge, MA. https://doi.org/10.7551/mitpress/5330.001.0001

Jackson, V. and Back, A. (2011). Teaching communication skills using role-play: An experience-based guide for educators. Journal of Palliative Medicine, 14(6): 775-80. Available: https://doi.org/10.1089/jpm.2010.0493

Kokkinaki, T. and Kugiumutzakis, G. (2000). Basic aspects of vocal imitation in infant-parent interaction during the first 6 months. Journal of Reproductive and Infant Psychology, 18(3): 173-87. Available: https://doi.org/10.1080/713683042

Ladousse, G. P. (2004). Role play. Oxford University Press.UK.: Oxford.

Lindholm-Leary, K. and Block, N. (2010). Achievement in predominantly low SES/ Hispanic dual language schools. International Journal of Bilingual Education and Bilingualism, 13(1): 43-60. Available: https://doi.org/10.1080/13670050902777546

Liu, F. and Ding, Y. (2009). Role-play in english language teaching. Asian Social Science: 140-43. Available: https://doi.org/10.5539/ass.v5n10p140

Magocsa, L. (2011). The role of imitation in second language acquisition. INTED2011 Proceedings. 5244-51. https://library.iated.org/view/MAGOCSA2011THE1

Meltzoff (2007). Infants' causal learning: Intervention, observation, imitation. Gopnik and Schulz. Causal Learning: Psychology, Philosophy, and Computation. Oxford University Press. https://doi.org/10.1093/acprof:oso/9780195176803.003.0003

Meltzoff and Prinz, W. (2002). An Introduction to the Imitative Mind and Brain. The imitative mind: Development, Evolution, and Brain Bases. Cambridge University Press: New York, USA. 6: 1-16. https://doi.org/10.1017/CBO9780511489969

Meltzoff, Kuhl, P. K., Movellan, J. and Sejnowski, T. J. (2009). Foundations for a new science of learning. Science, 325(5938): 284-88. Available: https://doi.org/10.1126/science.1175626

Nielsen, M. and Christie, T. (2008). Adult modelling facilitates young children's generation of novel pretend acts. Infant and Child Development, 17(2): 151-62. Available: https://doi.org/10.1002/icd.538

Oztop, E., Wolpert, D. and Kawato, M. (2005). Mental state inference using visual control parameters. Cognitive Brain Research, 22(2): 129-51. Available: https://doi.org/10.1016/j.cogbrainres.2004.08.004

Parra, E. B., Evans, C. A., Fletcher, T. and Combs, M. C. (2014). The psychological impact of English language. Journal of Multilingual Education Research, 5(4): 33-65. Available: https://files.eric.ed.gov/fulltext/EJ1176131.pdf 
Pickering, M. and Garrod, S. (2004). Toward a mechanistic psychology of dialogue. Behavioral and Brain Sciences, 27(2): 169-90. Available: https://doi.org/10.1017/S0140525X04000056

Prodanovska, V., 2017. "A Study of Proper Pronunciation as a Factor for Successful Communication." In $C B U$ International Conference on Innovations in Science and Education. Prague. . pp. 778-83.

Rojczyk, A., 2012. "Spontaneous phonetic imitation of L2 vowels in a rapid shadowing task." In Paper presented at Pronunciation in Second Language Learning and Teaching 2012. Vancouver Canada.

Rosselli, M., Ardila, A., Matute, E. and Vélez-Uribe, I. (2014). Language development across the life span: A neuropsychological/ neuroimaging perspective. Neuroscience Journal: 1-21. Available: https://doi.org/10.1155/2014/585237

Samifanni, F. (2020). The key into learning a new language: Do not just teach the language, localize first. European Journal of Education Studies, 7(2): 351-63. Available: https://doi:10.5281/zenodo.3742488

Schoop, M. (2001). An introduction to the language-action perspective. ACM SIGGROUP Bulletin, 22(2): 3-8. Available: https://doi.org/10.1145/605676.605677

Schwartz, J., Basirat, A., Ménard, L. and Sato, M. (2012). The Perception-for-Action-Control Theory (PACT): A Percepto-motor theory of speech perception. Journal of Neurolinguistics, 25: 336-54. Available: https://doi.org/10.1016/j.jneuroling.2009.12.004

Shepard, C. A., Giles, H. and Le Poire, B. (2001). Communication accommodation theory. In w. P. (eds), the new handbook of language and social psychology. John Wiley and Sons: Chichester.

Shockley, C., Richardson, D. and Dale, R. (2009). Conversation and coordinative structures. Top. Cogn. Sci., 1: 30519. Available: https://doi.org/10.1111/j.1756-8765.2009.01021.x

Speak, H. (2014). The importance of correct pronunciation. Available: https://www.hopespeak.com/blog/theimportance-of-correct-pronunciation/

Stivers, T., Enfield, N. J., Brown, P., Englert, C., Hayashi, M. and Heinemann, T. (2009). Universals and cultural variation in turn-taking in conversation. Proc. Natl. Acad. Sci. U S A, 106: 10587-92. Available: https://doi.org/10.1073/pnas.0903616106

Vygotsky, L. S. (1978). Mind in society: the development of higher psychological processes. Harvard University Press: Cambridge, MA.

Weigand, H. (2003). The language/ action perspective. Data and Knowledge Engineering, 47(3): 299-300. Available: https://doi.org/10.1016/j.datak.2003.09.001

Yamaoka, T. (2006). On the importance of imitation and repetition in foreign language learning. ARELE: Annual Review of English Language Education in Japan, 17: 1-10. Available: https://doi.org/10.20581/arele.17.0 1

Zalaghi, H. and Khazaei, M. (2016). The role of deductive and inductive reasoning in accounting research and standard setting. Asian Journal of Finance and Accounting, 8(1): 227-39. Available: https://doi.org/10.5296/ajfa.v8i1.8148

Zukow-Goldring, P. (2012). Assisted imitation: first steps in the seed model of language development. Language Sciences, 34(5): 569-82. Available: https://doi.org/10.1016/j.langsci.2012.03.012 